\title{
Only the Size of Resected Polyps Is an Independent Risk Factor for Delayed Postpolypectomy Hemorrhage: A 10- Year Single-Center Case-Control Study
}

\author{
Hee Seok Moon, Sun Wook Park, Dong Hwan Kim, Sun Hyung Kang, Jae Kyu Sung, Hyun Yong Jeong \\ Department of Internal Medicine, Chungnam National University School of Medicine, Daejeon, Korea
}

Purpose: A colonoscopic polypectomy is an important procedure for preventing colorectal cancer, but it is not free from complications. Delayed hemorrhage after a colonoscopic polypectomy is one infrequent, but serious, complication. The aim of this study was to identify the risk factors for delayed hemorrhage after a colonoscopic polypectomy.

Methods: This was a retrospective case-control study based on medical records from a single gastroenterology center. The records of 7,217 patients who underwent a colonoscopic polypectomy between March 2002 and March 2012 were reviewed, and 92 patients and 276 controls were selected. Data collected included comorbidity, use of antiplatelet agents, size and number of resected polyps, histology and gross morphology of resected polyps, resection method, and use of prophylactic hemostasis.

Results: The average time between the procedure and bleeding was $2.71 \pm 1.55$ days. Univariate and multivariate analyses revealed that the size of the polyps was the only and most important predictor of delayed hemorrhage after a colonoscopic polypectomy (odds ratio, 2.06; 95\% confidence interval, 1.12-1.27; $\mathrm{P}=0.03$ ).

Conclusion: The size of resected polyps was the only independent risk factor for delayed bleeding after a colonoscopic polypectomy. The size of a polyp, as revealed by the colonoscopic procedure, may aid in making decisions, such as the decision to conduct a prophylactic hemostatic procedure.

\section{Keywords: Colonoscopy; Polypectomy; Complication; Hemorrhage}

\section{INTRODUCTION}

A colonoscopic polypectomy significantly reduces the incidence of colorectal cancer and cancer-related mortality [1-4], but it is accompanied by several complications. Of these, hemorrhage is the most common complication [5-10]. Delayed hemorrhage following a polypectomy occurs between 3 to 7 days after the procedure, and its incidence is commonly reported to range between

Received: November 20, 2013 - Accepted: March 24, 2014

Correspondence to: Hyun Yong Jeong, M.D.

Department of Internal Medicine, Chungnam National University School of Medicine, 266 Munhwa-ro, Jung-gu, Daejeon 301-747, Korea

Tel: +82-42-280-7143, Fax: +82-42-280-4553

E-mail: jeonghy@cnuh.co.kr

(C) 2014 The Korean Society of Coloproctology

This is an open-access article distributed under the terms of the Creative Commons Attribution NonCommercial License (http://creativecommons.org/licenses/by-nc/3.0) which permits unrestricted noncommercial use, distribution, and reproduction in any medium, provided the original work is properly cited.
$0.6 \%$ and $0.9 \%$ [5-9]. Postpolypectomy delayed hemorrhage is unpredictable and can occur after hospital discharge; therefore, it requires attention. Some retrospective case-control studies have endeavored to identify the risk factors associated with delayed hemorrhage after a colonoscopic polypectomy [11-15] and have indicated that the size, shape, and location (right hemicolon) of the polyp, a sessile polyp type, and the endoscopist's experience are the key risk factors for delayed postpolypectomy hemorrhage [11-15]. Our center carried out a ten-year single-center case-control study to identify the risk factors associated with delayed postpolypectomy hemorrhage.

\section{METHODS}

\section{Study population and design}

The study retrospectively examined the medical records of patients who underwent a colonoscopic polypectomy at a single gastroenterology center at Chungnam National University Hospi- 
tal of Korea from March 2002 to March 2012. Delayed postpolypectomy hemorrhage was defined as the more than one occurrence of overt bleeding per anus or as a decrease in hemoglobin of more than $1 \mathrm{~g} / \mathrm{dL}$ starting at least 6 hours after the colonoscopy. The case group consisted of patients who had undergone a delayed postpolypectomy; each delayed hemorrhage case had also undergone a therapeutic colonoscopy. The control group consisted of patients who had undergone an uncomplicated polypectomy 7 days earlier.

Among the 8,327 patients who had undergone a colonoscopic polypectomy, delayed postpolypectomy hemorrhage occurred in 92 patients. From the 8,235 remaining patients $(8,327-8,392)$, we selected 276 patients for the control group, triple the number of patients experiencing postpolypectomy hemorrhage. For sampling, we applied a random sample extraction method. We categorized the hemorrhage group and the control group according to gender and age (less than 29 years old/30-39 years old/40-49 years old/50-59 years old/more than 70 years old); then, we applied a serial number to each category [12-14].

\section{Methods}

The risk factors for delayed hemorrhage were classified according to the patient, polyp, and procedure. Patient-related factors consisted of age, sex, comorbidity (hypertension, diabetes mellitus, cerebral vascular accident, coronary heart disease), and use of antiplatelets. Polyp-related factors included the size, number, location, and gross morphology of the polyp, and histologic findings. The sizes of the polyps were measured based on the sizes reported in the biopsy results. The locations of the polyps were divided into right (cecum, ascending colon) and left (transverse colon, descending colon, sigmoid colon, and rectum). The gross morphologies of the polyps were classified as pedunculated, semipedunculated, and sessile according to the presence or absence of a stalk. Histologically, the polyps were classified as hyperplastic polyps, adenomas, and adenocarcinomas. Procedure-related risk factors included resection methods (snare polypectomy or endoscopic

Table 1. Basic characteristics and underlying condition-related risk factors for delayed postpolypectomy hemorrhage

\begin{tabular}{lccc}
\hline Characteristic & Hemorrhage $(\mathrm{n}=92)$ & Control $(\mathrm{n}=276)$ & P-value \\
\hline Age $(\mathrm{yr})$ & $60.08 \pm 13.36$ & $60.62 \pm 12.27$ & 0.73 \\
Sex & & & 0.86 \\
$\quad$ Male & $79(85.9)$ & $239(86.6)$ & \\
Female & $13(14.1)$ & $37(13.4)$ & \\
Hypertension & $32(34.8)$ & $99(35.9)$ & 0.90 \\
Diabetes mellitus & $18(19.6)$ & $99(35.9)$ & 1.00 \\
Cerebral vascular accident & $8(8.7)$ & $19(6.9)$ & 0.64 \\
Coronary heart diasese & $11(12.0)$ & $34(12.3)$ & 1.00 \\
Ues of antiplatelets & $31(33.7)$ & $84(30.4)$ & 0.60 \\
\hline
\end{tabular}

Values are presented as mean \pm standard deviation or number (\%). mucosal resection) and use of prophylactic hemostasis.

\section{Statistical analysis}

Statistical analyses were performed using SPSS ver. 12.0 (SPSS Inc., Chicago, IL, USA). Categorical data were presented as frequencies and were compared using chi-square statistics or the Fisher exact test. Continuous data were presented as means \pm 1 standard deviation and were compared using the Student $t$-test. Independent predictors for the occurrence of delayed postpolypectomy hemorrhage were determined using a multivariate logistic regression analysis. Variables that were predictive at the 0.1 level by using a univariate analysis were entered into the final multivariate analysis. A P-value less than 0.05 denoted statistical significance.

\section{RESULTS}

Over a 10-year interval, 8,327 patients underwent a colonoscopic polypectomy. Delayed postpolypectomy hemorrhage occurred in 92 patients (1.1\%), who were selected as the case group. The average time between the procedure and bleeding was $2.71 \pm 1.55$ days. The control group consisted of 276 patients who had experienced an uneventful procedure. The baseline clinical characteristics of the case and the control groups were not significantly different (Table 1).

Neither comorbidity nor use of antiplatelets had any significant association with delayed postpolypectomy hemorrhage (Table 1). No statistically significant difference was found between a snare polypectomy and an endoscopic mucosal resection in terms of inducing delayed postpolypectomy hemorrhage. The use of prophylactic hemostasis also showed no significant difference (Table 2).

Both the univariate and the multivariate analyses showed that the size of the resected polyps was the only, and most important, predictor of delayed hemorrhage after a colonoscopic polypectomy (odds ratio [OR], 2.06; 95\% confidence interval [CI], 1.12-1.27; P = $0.03)$. The average size of the resected polyps in the case group was $11.83 \pm 4.47 \mathrm{~mm}$, and in the control group, it was $10.70 \pm 3.66 \mathrm{~mm}$. The size of resected polyps was slightly larger in the case group than in the control group $(\mathrm{P}=0.03)$. However, the multivariate analysis revealed that the risk of delayed bleeding increased by 24 percent for every $1 \mathrm{~mm}$ increase in the size of the resected polyp (OR, 1.24; $95 \%$ CI, 1.12-1.27; $\mathrm{P}=0.03$ ) (Tables 3, 4).

Table 2. Procedure-related factors for delayed postpolypectomy hemorrhage

\begin{tabular}{llcc}
\hline & Hemorrhage & Control & P-value \\
\hline Resection method & & & 0.90 \\
Snare polypectomy & $85(92.4)$ & $260(94.2)$ & \\
Endoscopic mucosal resection & $15(7.6)$ & $16(5.8)$ & \\
Use of prophylactic hemostasis & $48(52.2)$ & $145(52.5)$ & 1.00 \\
\hline
\end{tabular}

Values are presented as number (\%). 
Table 3. Polyp-related factors for delayed postpolypectomy hemorrhage

\begin{tabular}{lccc}
\hline Variable & Hemorrhage & Control & P-value \\
\hline Size of resected polyp (mm) & $11.83 \pm 4.47$ & $10.70 \pm 3.66$ & 0.03 \\
No. of resected polyps & $2.61 \pm 1.39$ & $2.45 \pm 1.30$ & 0.32 \\
Location & & & 0.09 \\
$\quad$ Right colon ${ }^{\mathrm{a}}$ & $56(60.9)$ & $139(50.4)$ & \\
$\quad$ Left colon & & \\
Histology & $36(39.1)$ & $137(49.1)$ & \\
$\quad$ Hyperplastic polyp & $4(4.3)$ & $13(4.7)$ & \\
Adenoma & $82(89.1)$ & $246(89.1)$ & \\
$\quad$ Adenocarcinoma & $6(6.5)$ & $17(6.2)$ & \\
Gross morphology of polyp & & & 0.88 \\
$\quad$ Pedunculated & $32(34.8)$ & $95(34.4)$ & \\
Semipedunculated & $35(38.0)$ & $103(37.3)$ & \\
$\quad$ Sessile & $25(27.2)$ & $78(28.3)$ & \\
\hline
\end{tabular}

Values are presented as mean \pm standard deviation or number (\%).

${ }^{a}$ Cecum and ascending colon. ${ }^{\mathrm{b}}$ Transverse colon, descending colon, sigmoid colon, and rectum.

\section{DISCUSSION}

A colonoscopic polypectomy is an effective tool for preventing colorectal cancer [1-4]; however, it can induce several complications $[5,6]$. The most commonly encountered complications of a polypectomy are hemorrhage and perforation [7-10]. Postpolypectomy hemorrhage can be classified as immediate (defined as occurring during the procedure) or delayed (defined as occurring after the procedure) [6]. Approximately two-thirds of delayed hemorrhages stop spontaneously, although on rare occasions, some patients require a transfusion or further intensive treatment [5-7]. In Korea, in particular, many colonoscopic polypectomy procedures are performed on an out-patient basis, which means that delayed hemorrhage can occur outside the hospital, which raises concerns.

The risk factors for delayed postpolypectomy hemorrhage have been assessed by several studies [11-15]. For example, Watabe et al. [15] suggested that hypertension was a significant risk factor for delayed postpolypectomy hemorrhage. However, in our study, none of the comorbidities significantly affected the patient's related risk for delayed postpolypectomy hemorrhage.

The effect of antiplatelets use on postpolypectomy bleeding has been equivocal according to previous studies [16, 17]. Use of antiplatelets was not associated with delayed postpolypectomy hemorrhage in the present study. The American Society for Gastrointestinal Endoscopy [18] suggested that the use of a single antiplatelet agent should not be terminated prior to the polypectomy; our study would seem to support this recommendation.

In previous studies, polyp-related risk factors were significantly
Table 4. Multivariate analysis of risk factors for delayed postpolypectomy hemorrhage

\begin{tabular}{lccc}
\hline Variable & Odds ratio & $\begin{array}{c}95 \% \\
\text { confidence interval }\end{array}$ & P-value \\
\hline Hypertension & 1.10 & $0.82-2.96$ & 0.429 \\
Use of prophylactic hemostasis & 1.07 & $0.94-1.10$ & 0.766 \\
Right side location of polyp & 2.17 & $0.61-8.35$ & 0.221 \\
Size of resected polyp (mm) & 1.24 & $1.12-1.27$ & 0.030 \\
No. of resected polyp & 1.09 & $0.84-1.19$ & 0.367 \\
\hline
\end{tabular}

more important risk factors for postpolypectomy delayed hemorrhage than were either patient- or procedure-related risk factors [11-14]. The size, number, location (right colon), and sessile form of the polyp were suggested as polyp-related risk factors [11-15]. Polyp size was determined in several previous studies to be the most reliable factor for predicting hemorrhage [11, 12, 14]. Similarly, in our study, the size of the resected polyps was the only independent risk factor for delayed bleeding, and the risk of delayed bleeding increased by $24 \%$ for every $1-\mathrm{mm}$ increase in the resected polyp size (OR, 1.24; 95\% CI, 1.12-1.27; $\mathrm{P}=0.03$ ).

Evaluation of procedure-related factors indicated no significant independent factor related to delayed postpolypectomy hemorrhage. Some studies have suggested that the endoscopist's experience can be an independent risk factor for delayed postpolypectomy hemorrhage $[12,13]$, but we included cases that had been performed by operators whose experience with a polypectomy was two or more years. Consequently, we did not analyze the endoscopist's experience as a risk factor. Some studies have suggested the use of argon plasma coagulation or endoclips for the prevention of postpolypectomy bleeding, but the effects of their use are still being debated [19-22]. Endoscopic mucosal resection, snare polypectomy, and use of prophylactic hemostasis had no significant effects on the risk of delayed hemorrhage in our study.

The number of subjects in the control group in our study was three times the number of subjects in the patient group, which helped in assessing highly-significant risk factors. However, our study also had some limitations. For example, it was conducted at a single center as a retrospective study based on medical records. Although we collected cases that were performed by surgeons who had two or more years' experience in the polypectomy procedure, our study could not reflect each endoscopist's skills, which may have had an influence on postpolypectomy complications, including delayed hemorrhage. We suggest that a large, multicenter, prospective study is needed to assess the risk factors for delayed postpolypectomy hemorrhage. We believe this would help in establishing effective guidelines for preventing this type of hemorrhage.

In conclusion, the size of the resected polyp is the only independent risk factor for delayed postpolypectomy hemorrhage. Surgeons who plan to perform a polypectomy of larger-sized polyps 
should keep the possibility of delayed hemorrhage in mind and should consider conducting a prophylactic hemostatic procedure before the polypectomy.

\section{CONFLICT OF INTEREST}

No potential conflict of interest relevant to this article was reported.

\section{REFERENCES}

1. Winawer SJ, Zauber AG, Ho MN, O’Brien MJ, Gottlieb LS, Sternberg SS, et al. Prevention of colorectal cancer by colonoscopic polypectomy. The National Polyp Study Workgroup. N Engl J Med 1993;329:1977-81.

2. Macrae FA, Tan KG, Williams CB. Towards safer colonoscopy: a report on the complications of 5,000 diagnostic or therapeutic colonoscopies. Gut 1983;24:376-83.

3. Yang DH, Hong SN, Kim YH, Hong SP, Shin SJ, Kim SE, et al. Korean guidelines for postpolypectomy colonoscopy surveillance. Clin Endosc 2012;45:44-61.

4. Manser CN, Bachmann LM, Brunner J, Hunold F, Bauerfeind P, Marbet UA. Colonoscopy screening markedly reduces the occurrence of colon carcinomas and carcinoma-related death: a closed cohort study. Gastrointest Endosc 2012;76:110-7.

5. Heldwein W, Dollhopf M, Rosch T, Meining A, Schmidtsdorff G, Hasford J, et al. The Munich Polypectomy Study (MUPS): prospective analysis of complications and risk factors in 4,000 colonic snare polypectomies. Endoscopy 2005;37:1116-22.

6. Fatima H, Rex DK. Minimizing endoscopic complications: colonoscopic polypectomy. Gastrointest Endosc Clin N Am 2007;17: 145-56.

7. Sorbi D, Norton I, Conio M, Balm R, Zinsmeister A, Gostout CJ. Postpolypectomy lower GI bleeding: descriptive analysis. Gastrointest Endosc 2000;51:690-6.

8. Kapetanos D, Beltsis A, Chatzimavroudis G, Katsinelos P. Postpolypectomy bleeding: incidence, risk factors, prevention, and management. Surg Laparosc Endosc Percutan Tech 2012;22:102-7.

9. Church JM. Experience in the endoscopic management of large colonic polyps. ANZ J Surg 2003;73:988-95.

10. Baillie J. Postpolypectomy bleeding. Am J Gastroenterol 2007;102: 1151-3.
11. Kim JH, Lee HJ, Ahn JW, Cheung DY, Kim JI, Park SH, et al. Risk factors for delayed post-polypectomy hemorrhage: a case-control study. J Gastroenterol Hepatol 2013;28:645-9.

12. Bae GH, Jung JT, Kwon JG, Kim EY, Park JH, Seo JH, et al. Risk factors of delayed bleeding after colonoscopic polypectomy: casecontrol study. Korean J Gastroenterol 2012;59:423-7.

13. Wu XR, Church JM, Jarrar A, Liang J, Kalady MF. Risk factors for delayed postpolypectomy bleeding: how to minimize your patients' risk. Int J Colorectal Dis 2013;28:1127-34.

14. Buddingh KT, Herngreen T, Haringsma J, van der Zwet WC, Vleggaar FP, Breumelhof R, et al. Location in the right hemi-colon is an independent risk factor for delayed post-polypectomy hemorrhage: a multi-center case-control study. Am J Gastroenterol 2011;106:1119-24.

15. Watabe H, Yamaji Y, Okamoto M, Kondo S, Ohta M, Ikenoue T, et al. Risk assessment for delayed hemorrhagic complication of colonic polypectomy: polyp-related factors and patient-related factors. Gastrointest Endosc 2006;64:73-8.

16. Pan A, Schlup M, Lubcke R, Chou A, Schultz M. The role of aspirin in post-polypectomy bleeding: a retrospective survey. BMC Gastroenterol 2012;12:138.

17. Manocha D, Singh M, Mehta N, Murthy UK. Bleeding risk after invasive procedures in aspirin/NSAID users: polypectomy study in veterans. Am J Med 2012;125:1222-7.

18. ASGE Standards of Practice Committee, Anderson MA, Ben-Menachem T, Gan SI, Appalaneni V, Banerjee S, et al. Management of antithrombotic agents for endoscopic procedures. Gastrointest Endosc 2009;70:1060-70.

19. Cipolletta L, Bianco MA, Rotondano G, Catalano M, Prisco A, De Simone T. Endoclip-assisted resection of large pedunculated colon polyps. Gastrointest Endosc 1999;50:405-6.

20. Lee CK, Lee SH, Park JY, Lee TH, Chung IK, Park SH, et al. Prophylactic argon plasma coagulation ablation does not decrease delayed postpolypectomy bleeding. Gastrointest Endosc 2009;70: 353-61.

21. Katsinelos P, Kountouras J, Paroutoglou G, Beltsis A, Chatzimavroudis $\mathrm{G}$, Zavos $\mathrm{C}$, et al. Endoloop-assisted polypectomy for large pedunculated colorectal polyps. Surg Endosc 2006;20:1257-61.

22. Quintanilla E, Castro JL, Rabago LR, Chico I, Olivares A, Ortega $\mathrm{A}$, et al. Is the use of prophylactic hemoclips in the endoscopic resection of large pedunculated polyps useful? A prospective and randomized study. J Interv Gastroenterol 2012;2:183-8. 